\title{
Life Project for Adolescents: A Concept Analysis
}

\author{
Rosalva C. Barbosa-Martinez ${ }^{1}$, Jose M. Ramirez-Aranda ${ }^{2}$, Bertha Cecilia Salazar-González ${ }^{3}$, Raquel A. \\ Benavides-Torres ${ }^{4}$, Jane D. Champion ${ }^{5} \&$ Julia Gallegos-Guajardo $^{6}$ \\ ${ }^{1}$ Universidad Autónoma de Nuevo León, School of Nursing, Centro de Investigación y Desarrollo en Ciencias de la \\ Salud, Nuevo León, México. \\ ${ }^{2}$ Universidad Autónoma de Nuevo León, School of Medicine, Nuevo León, México. \\ ${ }^{3}$ Universidad Autónoma de Nuevo León, School of Nursing, Nuevo León, México. \\ ${ }^{4}$ Universidad Autónoma de Nuevo León, School of Nursing, Centro de Investigación y Desarrollo en Ciencias de la \\ Salud, Nuevo León, México. \\ ${ }^{5}$ School of Nursing, University of Texas at Austin, Texas, United States. \\ ${ }^{6}$ Department of Psychology, University of Monterrey, Nuevo León, México. \\ Correspondence: Raquel A. Benavides-Torres, School of Nursing, Centro de Investigación y Desarrollo en Ciencias de \\ la Salud, Nuevo León, México.
}

Received: March 1, 2016

doi:10.11114/ijsss.v4i5.1490
Accepted: March 21, 2016

Available online: March 23, 2016

\begin{abstract}
It is essential to identify protective factors during adolescence due to its high incidence on risk behaviors. One of these factors is to have a life project that influences adolescent decision-making. The concept of life project has mainly been linked to teen pregnancy, depression and suicide; however, some authors agree that the concept is not clearly defined. Therefore, the objective of this paper is to define the concept of adolescent life project, using the methodology developed by Walker and Avant for concept analysis. The following steps were followed are: select a concept, determining the purpose of analysis, identifying all uses of the concept, determining the defining attributes, identifying a model, a borderline and a contrary cases, identifying history and consequences of the concept, and finally defining empirical referents. After the analysis, the final definition of the concept of adolescent life project includes the set of desires, future plans and actions necessary to accomplish it that influence the adolescent decisions. Knowing the importance of this concept when working with adolescents may guide development more effective interventions.
\end{abstract}

Keywords: Aspirations, Adolescents, Concept formation, Life project

\section{Introduction}

Adolescence is characterized by a period of great vulnerability, exposing the teen to performing behavior such as teenage pregnancy, sexual risk behavior, drug abuse, among others. There are several factors that influence the decision-making of adolescents, so it is of great importance to continue efforts towards identification and analysis of these factors. One of the protective factors that have been identified during the period of adolescence is the life project (Ramirez-Aranda et al, 2013). The concept of life project has mainly been linked to teen pregnancy, depression and suicide; however, the authors agree that the concept is not clearly defined (Baeza, Poo, Vasquez, Muñoz \& Vallejos, 2007; Clark, Poulin \& Kohler, 2009; Harris et al, 2007; Phipps, Salak, Nunes \& Rosengard, 2011; Ramirez-Aranda et al, 2013).

The nursing profession and other professions should develop interventions to reduce risk in adolescent behavior, in which the project life plays an important role. Interventions should be based on a theory, which is formed by concepts. When one of the concepts is not well defined, it is necessary to analyze its attributes and characteristics for further clarification. In this order of ideas, Walker and Avant (2011) note that: "The concept analysis is a means for clarifying the meaning of concepts for various purposes. Since concepts are the basic building blocks for theory building, it is critical to have the concepts sound and strong. So concept analysis is a rather good way to begin to understand how one thinks logically related to terms and their definitions and uses in theory development" (p. 155).

The concept of life project has however been linked to future aspirations, the desire to be productive, career goals or 
plans to continue studying, getting married and having children and a job (Baeza et al., 2007; Clark et al., 2009; Harris et al., 2007; Phipps et al., 2011; Ramirez-Aranda et al., 2013). Due to the above, it is necessary to define the project of adolescent life, to analyze how it influences decision-making of the individual and subsequently generate interventions where training serve as a strategy to reduce risk behaviors.

Thus, the purpose of this paper is to define the concept of life project for adolescents. The analysis of the concept of adolescent life project, is necessary and relevant to the nursing profession, to be used within the framework in the development of interventions aimed especially at sexual health; however, this concept can be used in various professions, such as psychology, medicine and social work, as the life project concept has been linked with pregnancy, depression and suicide.

\section{Method}

There are several ways to define concepts, one of the most recognized works within the nursing profession is that conducted by Walker and Avant, who specifies the steps for the construction of knowledge from the point of view of nursing, one strategy is concept analysis. Walker and Avant (2011) report that: "The concept analysis is a process of examining the basic elements for a concept. If we know what counts when we describe a concept it helps us to distinguish a concept from others that are similar, but not the same as, that concept. It allows us to distinguish the likeness and unlikeness between concepts" (p. 158).

To approach the project of life concept in adolescents, the methodology proposed by Walker and Avant (2011) was used. They proposed a strategy consisting of the following steps: select a concept, determine the purpose of analysis, identification of all uses of the concept, determine the defining attributes, identify a model, borderline and contrary case, identify antecedents and consequences of the concept, and finally, definition of empirical referents. Several analysis concepts have been developed following the methodology proposed by Walker and Avant, for example, overcoming, compassion fatigue within nursing practice, resilience, person centered care, health literacy, teamwork, , and others (Brush et al., 2011; Coetzee \& Klopper, 2010; Earvolino-Ramirez, 2007; Morgan \& Yoder, 2012; Speros, 2005; Xyrichis \& Ream, 2008).

\section{Results}

\subsection{Select a concept}

This step is defined by Walker and Avant (2011) by "examining the significance of the concept in its various contexts" (p. 160). From this perspective, its necessary show the etymology of the concept; the word project comes from the Latin "proiectus", which refers to a set of documents, calculations, and drawings that are made to give an idea of how a work of architecture or engineering should be and what it will cost (Dictionary of the Royal Spanish Academy [DRAE], 2001). According to an etymological dictionary (2015), the Latin "proiectus" is derived from the verb "proicere": pro (forward) and "iacere" (throw), therefore, project means launching forward, towards the future.

D'Angelo (2000) states that the life project integrates fundamental directions and the individual's modes of action in the broad context of determining the relationship with the society. The life project is the structure that expresses openness to the domain of the future; it means essential directions and critical areas that require vital decisions. Thus, the configuration, content and direction of the life project, due to its nature, origin and destination are linked to the social status of the individual, both in its current expression as well as in an early perspective of anticipated future events, which are open to the definition of place and tasks in a given society.

The life project has been linked with hopes and expectations of life. According to the DRAE (2001) hope is the action or effect of wanting or desiring something; expectation is derived from the Latin "expectatum", which means watched or seen; it is the hope of achieving or getting something; a reasonable chance of something happening.

When analyzing the definitions of life project (hopes and expectation in life) we find the following difference: hope and life expectation refer to the desire to make something happen and life project includes the tasks that must be performed to achieve the desired effect. It is also mentioned that these tasks must be interrelated and focused on achieving the proposed goal.

Bordignon (2005) establishes that the life project implies that the individual has the cognitive ability to want to carry out a proposed plan and, according to Erickson's psychosocial theory, a 13-21 year-old-adolescent (sic) is psychologically and cognitively prepared to plan his/her life. The establishment of an identity, personality, hierarchy of values, and sexual identity predominates at this stage. This is confirmed by D'Angelo (2000) who states that the components required to build the life project, reach full development in stages following adolescence.

\subsection{Determine the purpose of analysis}

It has been established the need to integrate the life project as a way of directing adolescent sexual behavior towards 
meeting goals. However, a specific way in which both, the adolescent life project and the factors needed to build it, influence sexual behavior has not been found; therefore research studies are proposed. It is considered that, as a first step, the meaning of the concept of adolescent life project should be established to promote its awareness, attributes, and consequences. Subsequently, we must study the interrelationship of this concept with other factors, such as sexual behavior.

\subsection{Identification of all uses of the concept}

Walker and Avant (2011) suggest in this step to use "dictionaries, thesauruses, colleagues, and available literature, identify as many uses of the concept as you can find....This review of literature helps you support or validate your ultimate choices of the defining attributes and provides the evidence base for your analysis" (p. 161). Therefore, the different uses of the concept shown through a literature review.

The concept of life project has been used by various disciplines in their field of interest. One of the most common ways to use this concept is in relation to the construction plans for a house or building. The concept has also been used with the proposal of taking action to meet a goal set in business, including time limits, resources, and budget.

The concept of life project has been implemented at different levels including individual, personal, family, and community. However, the predominant concept is the individual life project, which includes personal, family, school, and professional aspects. D'Angelo (2000) adds other aspects such as work, leisure, cultural, and socio-political activity, interpersonal relationships of friendship and love, organizational, and others.

As a result of a systematic search of the literature, we present a summary of studies in which the concept of life project is discussed. In some of these studies the concept of life project is considered as the future, aspirations, intentions and others.

Alonso, Bayarre and Artiles (2004) conducted a study with the aim of building an instrument to measure personal satisfaction in midlife women. In this research, the concept of life project is conceptualized as the future temporal structure of personality, which is represented by the ideals, intentions, aspirations, and goals that the subject outlines in life.

Hernandez (2006) conducted an exploratory study of the life project in the elderly. His main results point to a lack of the concept of life project in older adults. The lack of planning for the future and the considerable influence of having or not a life project has an effect on health status, income, education, subsequent plans, life satisfaction, and socioeconomic status.

Baeza et al. (2007) qualitatively studied factors related to unplanned pregnancy among adolescents, from the perspective of nulliparous students. According to their research, adolescents individually consider that the protective factors for unwanted pregnancy include a reflective ability and the generation of a life project. However, the definition of life project is not specified in the study.

Phipps et al. (2011) conducted an investigation to quantify the association between career aspirations and intentions of pregnancy in a cohort of pregnant adolescents. In this study, they describe career aspirations as a future project.

Harris et al. (2007) conducted a study to examine how relationships and qualities of young people influence adolescent sexual behavior. Nine qualities were described including future aspirations; a specific definition was not mentioned though.

Oman, Vesely and Aspy (2005) investigated how the relationship between nine juvenile qualities and four risky sexual behaviors can vary according to family structure. They reported that among other things, the qualities that young people living in single-parent households should have are future aspirations and good health practices (exercise/nutrition). A specific definition of future aspirations was not however indicated.

Clark et al. (2009) qualitatively studied marital aspirations with regards to sexual behavior of adolescents and youth in Malawi. They reported that marital aspirations play a more important role in premarital sex for women than for men. These findings established that marital aspirations are part of the life project.

\subsection{Determine the defining attributes}

Walker and Avant (2011) refer that "the effort is to ty to show the cluster of attributes that are the most frequently associated with the concept and that allow the analyst the broadest insight into the concept" (p. 162). About the attributes of the life project concept, D'Angelo (2000) refers that "the work for the construction of life projects in the adolescent ...... should be addressed in the context of projects reflective, creative, flexible, integrated harmonically and self-accomplishment" (p. 272).

To analyze the attributes of the concept life project mentioned by the DRAE (2001) and D'Angelo (2000), that is conclude that the attributes of the concept of adolescent life project are listed in Table 1; which are defined as follows:

1) Progressive: It advances and increases in quantity or perfection. Short, medium, and long term steps should be set.

2) Feasible: It can be done. The goals and proposed steps must be feasible and achievable in the time and manner 
established.

3) Coherent: It is connected, related or linked together. It must be consistent with the values, goals, personality, and desires of the adolescent.

4) Integral: It is global, total and includes all parts of a whole.

5) Dynamic: It includes a system of forces that lead to a goal.

6) Reflective: It requires a retrospective analysis of the strengths and weaknesses of the individual as well as future goals.

7) Creative: It uses various innovative strategies for the implementation and achievement of the proposed goal.

8) Harmoniously: All steps or activities are used to achieve the stated objective and complement each other.

9) Self-accomplishment: It allows for the achievement or fulfillment of the proposed target.

\subsection{Identify a model case}

Walker and Avant (2011) state that "a model case is an example of the use of the concept that demonstrates all the defining attributes of the concept. The model case should be a pure case of the concept, a paradigmatic example, or a pure exemplar" (p. 163). Below is an example of the concept model case that case is an example of the real life of an adolescent (named by authors "Fernanda") in relation to the project of life.

17-year-old adolescent Fernanda has mentioned that her personal life project is to get married, have three children and travel to Europe to see various cities. Concerning her professional life, she plans to be a veterinarian. Regarding her family, she plans to assist them financially so that her two younger sisters can complete a career education.

At this point, she has decided to finish high school education to study at the Veterinary school. She has a part-time job in a stationery store and indicates that this job allows her to pay for her personal and high school expenses. She has had a boyfriend for one year who is a first semester university student. They are both aware of the possible risk of a pregnancy and both have decided to avoid this risk. They want to finish their studies and financially support their families, and so it is important to them to avoid the risk of pregnancy. Fernanda says she does not want to get pregnant yet as she knows her behavior will set an example for her younger sisters. She also understands that having a child at this stage in her life will make it very difficult for her to fulfill her life project.

\subsection{Identify contrary and borderline cases}

Walker and Avant (2011) establish that "examining cases that are not exactly the same as the concept of interest but are similar to it or contrary to it in same ways will help you make better judgments about which defining attributes or characteristics have the best fit" (p. 164). A contrary case is shown below, where an adolescent has not established a life project, a borderline case, and where an adolescent knows that it is a life project but does not have it well established.

Contrary Case: Ana is an 18-year-old adolescent who has no life project. She is working for a company as a laborer and is currently pregnant. She mentions that she did not complete secondary school because she did not know what she wanted to study. Her parents told her that if she did not know what she wanted to study, then she had to work. Ana has worked for four years for a packaging company. She has had three boyfriends with whom she has had sex. She has been a co-worker's girlfriend for six months. They had sex two months after they began dating. They did not use any contraception because they believed it was not possible for a woman to get pregnant when having infrequent sex. She became pregnant after two months. The pregnancy made them both very afraid because they did not have plans to get married. They feel pressured by Anna's mother to get married before their child is born. The wedding has been organized by Ana's mother. She avoids addressing uncertainties about where they will live and how they will cover the cost of the wedding and the birth of their child.

Table 1. Attributes of life project concept

\begin{tabular}{|ll|}
\hline 1) Progressive & 6) Reflective \\
2) Feasible & 7) Creative \\
3) Coherent & 8) Harmoniously \\
4) Integral & 9) Self-accomplishment \\
5) Dynamic &
\end{tabular}

Borderline case: Veronica, is a pregnant 19-year-old adolescent currently working in a company as a laborer. She studied through high school because she did not know what to study, so her parents said she should work and has been doing it for four years. She has had three boyfriends with whom she had sexual relationships. She has been Luis' girlfriend for the last six months, who is a peer of her work team. After two months in a relationship they started having sex and did not use any contraceptive method because they believe that she cannot get pregnant because they don't have 
sex at a daily basis. Two months later, she realized she was pregnant. The news of the pregnancy made them both very afraid because they had no plans to get married and now feel pressured by Veronica's mother to do it before the birth of her son. The wedding is being organized by her mother given that she ignores how to plan it. She also don't know where they will live and where they will continue to work, plus how they will finance the wedding and the birth of her son.

\subsection{Identify antecedents and consequences}

The background that the adolescent must consider to build a life project is described by D'Angelo (2000) as the following:

1) Socio-demographic characteristics

2) Personal experience (life events and personal history, vital concerns and satisfaction and time use)

3) Meaning of life (values orientation and vital ideals) and vital personality orientations (towards different spheres of life)

4) Personal life plans (professional and other fields)

5) Personality (personal self-reflection, choice strategies of personal goals, personal self-determination, personal meaning and conflicts, or adaptive defense mechanisms and capabilities)

Hernandez (2006) believes that the construction of the life project is influenced by the state of one's health, education, subsequent plans, life satisfaction, and socioeconomic status.

As a consequence of the life project concept it is possible to mention that when a person fulfills one's life project based on the outlook or future plans, it follows that activities or behaviors will be focused on achieving their goals. This leads to obtaining results on an individual and social level. Individual consequences include personal fulfillment, exploiting potential and greater personal and professional achievements. Additional individual consequences include adopting a healthy lifestyle and preventing disease.

When the adolescent does not fulfill a life project, it is suggested that his/her activities or behaviors are not directed towards an established purpose thereby potentiating risky sexual behaviors. These behaviors substantially increase the risk of an unintended pregnancy and sexually transmitted infection.

When the adolescent's behavior is not consistent with their life project, it will usually be modified or destroyed. For example, Salazar-Arango, Acosta-Murcia, Lozano-Restrepo and Quintero-Camacho (2008) report that unintended pregnancy typically pressures adolescents to make decisions to drop out of school or get married. Socio-economic consequences are those associated with a higher prevalence of unintended pregnancies and sexually transmitted infection. Adolescents experiencing unintended pregnancies often have fewer opportunities for professional development because of lack of educational preparation. The lack of a life project has also been linked with depression, drug use and suicide. Hernandez (2006) states that one way to prevent suicide is to have a life project; a task for the future that must persist.

\subsection{Define empirical referents}

There is a need to develop instruments to measure the life project concept as it relates specifically to sexual behavior in adolescents for health promotion. Studies that describe the concept of life project have been performed using the qualitative paradigm, providing substantial information on the definition, characteristics and construction of the life project (Baeza et al., 2007; Clark et al., 2009; Harris et al, 2007; Oman et al., 2005; Phipps et al., 2011). In interviews conducted by the aforementioned authors issues have been considered, such as the activities undertaken to fulfill a life project, the factors that influence and hinder the construction of the life project and its main features, among others.

Regarding the quantitative paradigm, there are few studies that measure the life project concept; however, the following are important. Alonso et al. (2004) constructed an instrument to measure personal satisfaction in middle-aged women in which a subscale called "life project" is included. This instrument obtained a coefficient of 0.80 and a Cronbach's alpha of 0.94 , therefore this instrument had a high internal consistency.

Hernandez (2006) conducted an exploratory study on the life project in the elderly. To measure the life project, the author constructed a specific instrument for this research including questions such as how future plans, educational level and daily activities contribute to the life project. Gil-Galvan, R. and Gil-Galvan, J. (2013) constructed a questionnaire to specifically measure life project. They constructed questions about future plans, work and academic activities to achieve these plans and influences on the life project. However, the validity of the instrument was not mentioned.

\section{Discussion}

This analysis allows us to define the concept of adolescent life project as the set of future desires or plans and the 
necessary actions to meet the proposed goals. The life project influences current decisions among adolescents as the future must be built day by day and decisions that are made will have an effect on the future.

The dimensions included in the adolescent's life project are at individual, family, and community levels. The individual life project includes aspects of life, work, profession, family, leisure, cultural and socio-political activity, interpersonal relationships including friendships, romantic relationships and organizations. The background for construction of the life project includes socio-demographic characteristics, the status of personal experiences and personal goals and life plans as well as adolescent personality. The concept of adolescent life project can be used in various disciplines and with different approaches; however it must be conceptualized considering all these dimensions and this background.

This analysis of life project as a concept can be utilized and developed into professional nursing practice. The project of life and the aspect of health can contribute to the quality of life for patients to have the necessary tools to guide the construction of the project life and decision-making needed to comply.

In clinical practice, it is common for nurses to work in the care of adolescents and as professionals it is important to encourage the construction of life project due to the implications this has on the decisions and actions of daily life. This article explains the meaning and importance of the analysis of the "life project" concept and also gives nurses the necessary step for the construction thereof, through which it could guide the construction of the project life of any teenager, mainly in adolescents whom are more likely to have unplanned pregnancy or depression and anxiety.

When nurses encourage and guide the construction of the project of life, they are making interventions that can be integrated as part of an investigation and later the establishment of the life project and its performance can be assessed.

The concept of life project has mainly been linked to teen pregnancy, depression and suicide; however, some. Therefore, the objective of this paper is to define the, using the methodology developed by Walker and Avant for concept analysis. After the analysis, the final definition of the concept of adolescent life project included the set of desires, future plans and actions necessary to accomplish it that influence the adolescent's decisions. Knowing the importance of using this concept when working with adolescents it may possible to develop more effective interventions.

Table 2. Summary of Article Findings

\section{Article Summary}

What is already known about this topic:

1. The life project is a concept that is used in different fields but is not clearly defined

2. Several authors have used the life project of adolescent concepts relating it to teen pregnancy, depression and suicide.

3. The concept analysis allows the development of theories

What this paper adds:

1. The concept analysis of life project of adolescents is described under the methodology proposed by Walker and Avant

2. A definition of the life project of adolescents concept is provided

3. It shows the dimensions of the concept included

\section{Acknowledgements}

The paper was funded in part by a Pre-Doctoral Fellowship from Conacyt awarded to Rosalva C. Barbosa-Martinez.

\section{References}

Alonso, G. R., Bayarre, V. H., \& Artiles, V. L. (2004). Construcción de un instrumento para medir la satisfacción personal en mujeres de mediana edad. Revista Cubana de Salud Pública, 30(2). Retrieved from http://www.redalyc.org/articulo.oa?id=21430206

Baeza, W. B., Póo, A. M., Vásquez, P. O., Muñoz, N. S., \& Vallejos, V. C. (2007). Identificación de factores de riesgo y factores protectores del embarazo en adolescentes de la novena región. Revista Chilena de Obstetricia y Ginecología, 72(2), 76-81. Retrieved from http://dx.doi.org/10.4067/S0717-75262007000200002

Bordignon, N. A. (2005). El desarrollo psicosocial de Eric Erikson: El diagrama epigenético del adulto. Revista Lasallista de Investigación, 2(2), 50-63. Retrieved from http://www.redalyc.org/articulo.oa?id=69520210

Brush, B.L., Kirk, K., Gultekin, L. \& Baiardi, J. M. (2011). Overcoming: a concept analysis. Nursing forum, 46(3), 160-168. http://dx.doi.org/10.1111/j.1744-6198.2011.00227.x

Clark, S., Poulin, M., \& Kohler, H. P. (2009). Marital aspirations, sexual behaviors, and HIV/AIDS in rural Malawi. 
Journal of Marriage and Family, 71(2), 396-416. doi:10.1111/j.1741-3737.2009.00607.x. Retrieved from http://www.ncbi.nlm.nih.gov/pmc/articles/PMC2782839/

Coetzee, S. K., \& Klopper, H. C. (2010). Compassion fatigue within nursing practice: A concept analysis. Nursing \& health sciences, 12(2), 235-243. http://dx.doi.org/10.1111/j.1442-2018.2010.00526.x

D`Angelo, H. O. (2000). Proyecto de vida como categoría básica de interpretación de la identidad individual y social. Revista Cubana de Psicología, 17(3). Retrieved from http://pepsic.bvsalud.org/pdf/rcp/v17n3/08.pdf

Dictionary of the Royal Spanish Academy (2001). 22 a edición. Retrieved from http://www.rae.es/

Earvolino, R. M. (2007). Resilience: A concept analysis. Nursing forum, 42(2), 73-82. http://dx.doi.org/10.1111/j.1744-6198.2007.00070.x

Etymological Dictionary (2015). Retrieved from http://etimologias.dechile.net/?proyecto

Gil-Galván, R., \& Gil-Galván, F. (2013). How to use professional and life projects to guide university students towards optimal professional development. Procedia - Social and Behavioral Sciences, 93, 1901-1905. http://dx.doi.org/10.1016/j.sbspro.2013.10.137.

http://www.sciencedirect.com/science/article/pii/S1877042813035829

Harris, L., Oman, R. F., Vesely, S. K., Tolma, E. L., Aspy, C. B., Rodine, S., et al. (2007). Associations between youth assets and sexual activity: Does adult supervision play a role? Child: Care, Health and Development, 33(4), 448-454.http://dx.doi.org/10.1111/j.1365-2214.2006.00695.x http://onlinelibrary.wiley.com/doi/10.1111/j.1365-2214.2006.00695.x/abstract

Hernández, Z. Z. E. (2006). Estudio exploratorio sobre el proyecto de vida en el adulto mayor. Psicología y Salud, 16(1), 103-110. Retrieved from http://revistas.uv.mx/index.php/psicysalud/article/view/798/1448

Morgan, S., \& Yoder, L. H. (2012). A concept analysis of person-centered care. Journal of Holistic Nursing, 30(1), 6-15. http://dx.doi.org/10.1177/0898010111412189

Oman, R. F., Vesely, S. K., \& Aspy, C. B. (2005). Youth assets and sexual risk behavior: The importance of assets for youth residing in one-parent households. Perspectives on Sexual and Reproductive Health, 37(1), 25-31. HTTP://DX.DOI.ORG/10.1363/372505. Retrieved from https://www.guttmacher.org/pubs/journals/3702505.html

Phipps, M. G., Salak, J.R., Nunes, A. P., \& Rosengard, S. (2011). Career aspirations and pregnancy intentions in pregnant teens. Journal of Pediatric and Adolescent Gynecology, 24, 11-15. DOI:http://dx.doi.org/10.1016/j.jpag.2010.12.001. Retrieved from http://www.ncbi.nlm.nih.gov/pubmed/21256777

Ramírez-Aranda, J. M., Gómez-Gómez, C., Villarreal-Pérez, J. Z., García-Elizondo, F.J., Rodríguez-Rodríguez, I., Rosas-Herrera, C.H., et al. (2013). Factores de protección y riesgo del embarazo en la adolescencia. Medicina Universitaria; $15(59)$.

http://www.elsevier.es/es-revista-medicina-universitaria-304-articulo-factores-proteccion-riesgo-del-embarazo-902 08278

Salazar-Arango, A., Acosta-Murcia, M.M., Lozano-Restrepo, N., \& Quintero-Camacho, M.C. (2008). Consecuencias del embarazo en el estado civil de la madre joven: Estudio piloto en Bogotá, Colombia. Persona y Bioética, 12(2). Retrieved from http://www.redalyc.org/articulo.oa?id=83211487008

Speros, C. (2005). Health literacy: concept analysis. Journal of advanced nursing, 50(6), 633-640. http://dx.doi.org/10.1111/j.1365-2648.2005.03448.x

Villacis, V. C., Becerra C. D., \& Negrete, K. L. (2012). Adherencia al control prenatal en la Clínica de Gestantes Adolescentes del Hospital de Engativá de Bogota. Doctoral dissertation, Universidad Nacional de Colombia.

Walker, L. O., \& Avant, K. C. (2011). Strategies for theory construction in nursing (5th ed.) New Jersey: Pearson/Prentice Hall.

World Health Organization (2009). Bulletin of the World Health Organization; Adolescent pregnancy a culturally complex issue, 87, 405-484.

Xyrichis, A., \& Ream, E. (2008). Teamwork: a concept analysis. Journal of advanced nursing, 61(2), 232-241. http://dx.doi.org/10.1111/j.1365-2648.2007.04496.x

\section{(c)) EY}

This work is licensed under a Creative Commons Attribution 3.0 License. 